\title{
The Role of Pro-inflammatory and Anti-inflammatory Adipokines on Exercise-Induced Bronchospasm in Obese Adolescents Undergoing Treatment
}

\author{
Patrícia Leão da Silva PhD, Marco Túlio de Mello PhD, Nadia Carla Cheik PhD, \\ Priscila Lima Sanches MSc, Aline de Piano PhD, Flávia Campos Corgosinho MSc, \\ Raquel Munhoz da Silveira Campos MSc, June Carnier MSc, Daniela Inoue MSc, \\ Claudia MO do Nascimento PhD, Lila M Oyama PhD, Lian Tock MD, \\ Sérgio Tufik MD PhD, and Ana R Dâmaso PhD
}

\begin{abstract}
BACKGROUND: Recent studies have demonstrated a greater prevalence in exercise-induced bronchospasm (EIB) in obese adolescents. However, the role of pro-/anti-inflammatory adipokines and the repercussions of obesity treatment on EIB need to be explored further. Therefore, the objective of this study was to evaluate the role of pro-/anti-inflammatory adipokines on EIB in obese adolescents evaluated after long-term interdisciplinary therapy. METHODS: Thirty-five post-pubertal obese adolescents, including 20 non-EIB (body mass index [BMI] $36 \pm 5 \mathrm{~kg} / \mathrm{m}^{2}$ ) and $15 \mathrm{EIB}$ (BMI $36 \pm 5 \mathrm{~kg} / \mathrm{m}^{2}$ ), were enrolled in this study. Body composition was measured by plethysmography, using the BOD POD body composition system, and visceral fat was analyzed by ultrasound. Serum levels of adiponectin and leptin were analyzed. EIB and lung function were evaluated according to the American Thoracic Society criteria. Patients were recruited to a 1-year interdisciplinary intervention of weight loss, consisting of medical, nutritional, exercise, and psychological components. RESULTS: Anthropometrics and lung function variables improved significantly after the therapy in both groups. Furthermore we observed a reduction in EIB occurrence in obese adolescents after treatment. There was an increase in adiponectin levels and a reduction in leptin levels after the therapy. In addition, a low $\mathrm{FEV}_{1}$ value was a risk factor associated with EIB occurrence at baseline, and was correlated after treatment with changes in anthropometric and maximal $\mathrm{O}_{2}$ consumption values as well as the adipokines profile. CONCLUSIONS: In the present study it was demonstrated that 1 year of interdisciplinary therapy decreased EIB frequency in obese adolescents, paralleled by an increase in lung function and improvement in pro-/anti-inflammatory adipokines. Key words: obesity; adolescents; adipokines; bronchospasm; exercise-induced; treatment; interdisciplinary studies. [Respir Care 2012;57(4):572-582. (C) 2012 Daedalus Enterprises]
\end{abstract}

Dr Silva, Ms Sanches, Dr Piano, Ms Corgosinho, Ms Campos, Ms Carnier, Ms Inoue, Dr Nascimento, Dr Tock, and Dr Dâmaso are affiliated with the Postgraduate Program of Nutrition; Drs Nascimento and Oyama are affiliated with the Department of Physiology; Drs Mello and Tufik are affiliated with the Department of Psychobiology; and Dr Dâmaso is affiliated with the Department of Biosciences and the Postgraduate Program of Interdisciplinary Health Sciences, Universidade Federal de São Paulo, São Paulo, Brazil. Dr Cheik is affiliated with the Federal University of Uberlândia, Uberlândia, Brazil.

\footnotetext{
This research was partly supported by Associação Fundo de Incentivo à Pesquisa (AFIP), Conselho Nacional de Desenvolvimento Científico e Tecnológico (CNPq), Coordenação de Aperfeiçoamento de Pessoal de Nível Superior (CAPES), Fundação de Amparo à Pesquisa do Estado de São Paulo (FAPESP 2008/53069-0, FAPESP 2006/00684-3, FAPESP 98/14303-3), Centro de Excelência Esportiva (CENESP), Fundo de Auxilio ao Docente e ao Aluna (FADA), Centros de Pesquisa, Inovação e Difusão (CEPID) Sleep no. 98/14303-3 ST), and Universidade Federal de São Paulo, São Paulo, Brazil. The authors have disclosed no conflicts of interest.
} 


\section{Introduction}

Obesity is a multi-factorial condition that leads to social, psycho-social, and health problems. ${ }^{1}$ In 1997 , the World Health Organization declared obesity to be a global epidemic condition. ${ }^{2}$ According to the last survey, approximately $49 \%$ of the adult Brazilian population is currently obese or overweight. In addition, the prevalence of obesity in adolescents has more than doubled in the last 20 years. ${ }^{3}$ The health risks associated with obesity include effects on the respiratory system. ${ }^{4}$ The increase in fat deposits has been associated with a reduction in lung volume $^{4,5}$ and exercise-induced bronchospasm (EIB). ${ }^{6-8}$

EIB is defined as a $15 \%$ reduction in $\mathrm{FEV}_{1}$ due to the airway obstruction that occurs in association with exercise, without regard to the presence of chronic asthma. ${ }^{9}$ Recent studies have observed that the prevalence of EIB is greater in obese non-asthmatics, compared to non-obese individuals. ${ }^{6,7,10}$ Another study did not find any difference in EIB prevalence between non-asthmatic obese and non-obese boys. ${ }^{11}$

Collectively, these reports indicate that exercise tolerance may be lower, lung function may be compromised, and inflammation was up-regulated in obese, compared to lean, individuals. ${ }^{6-8,12}$ In this sense, previous studies observed a positive association between leptin levels and airway hyper-responsiveness. ${ }^{13,14}$ On the other hand, the adiponectin level has been shown to be a protective factor for asthma. ${ }^{15}$ However, obese subjects present hyperleptinemia and/or leptin resistance, as well as hypoadiponectinemia. ${ }^{16,17}$ These physiological changes may also be the mechanism linking increased fat deposits with reported EIB. ${ }^{4}$ Moreover, the adiponectin/leptin ratio has been used a biomarker for the inflammatory process related to obesity; however, the role of these interactions with EIB frequency has not been well explored.

There are multiple treatments for EIB, which can be divided into pharmacologic and non-pharmacologic categories. Pharmacologic agents include short- and long-acting $\beta_{2}$ adrenoceptor agonists, anti-cholinergics, mast cell stabilizing agents, inhaled corticosteroids, and leukotriene receptor antagonists. ${ }^{18,19}$ Previous studies have demonstrated the effectiveness of these medications for reducing the occurrence of EIB. ${ }^{20,21}$ However, other studies have demonstrated that there are some limitations of pharmacologic therapy, such as potential side effects, the effective-

Correspondence: Patrícia Leão da Silva MSc, Postgraduate Program of Nutrition, Universidade Federal de São Paulo, São Paulo, Brazil, Rua Marselhesa, 535 Vila Clementino, São Paulo, Brazil 04020-060. E-mail: patricialeao@cepebr.org.

DOI: $10.4187 /$ respcare.01307

\section{QUICK LOOK}

\section{Current knowledge}

Evidence suggests there is a greater prevalence of exercise-induced bronchospasm in obese adolescents. However, the role of pro-/anti-inflammatory adipokines and the repercussions of obesity treatment on exerciseinduced bronchospasm are not well described.

\section{What this paper contributes to our knowledge}

A 1-year interdisciplinary weight loss therapy combining exercise training with medical, nutritional, and psychological therapies decreased exercise-induced bronchospasm frequency in obese adolescents, increased lung function, and improved pro-/anti-inflammatory adipokines.

ness of each medication, the frequency of administration, the duration of action, bad taste, and tolerance level..21-24

Non-pharmacologic management includes physical conditioning, incorporating a warm-up before and a cool-down period after exercise, nasal breathing, avoidance of cold weather or environmental allergens, and using a face mask or other aid to warm and humidify inhaled air. ${ }^{19}$ Dietary modifications may also play a role in EIB. In this manner, Mickleborough et $\mathrm{al}^{25}$ demonstrated that dietary supplementation with fish oil for 3 weeks reduced symptoms of EIB in asthmatics, with less than a $10 \%$ fall in post-exercise $\mathrm{FEV}_{1}$. Despite many studies being conducted to date, there is no single agent that has been consistently shown to prevent EIB; moreover, the majority of the studies were with asthmatic patients. ${ }^{25-27}$ The goal of therapy is to allow patients with EIB to participate in vigorous activity without symptoms and difficulty. ${ }^{18}$ Although the level of evidence is not high for several of the non-pharmacologic therapies, most have little or no adverse effects. ${ }^{26,27}$

Therefore, non-pharmacologic treatment for EIB is an area with many questions for continued research. ${ }^{18,19}$ In fact, to our knowledge, no study has evaluated the obesityrelated inflammatory biomarkers and their influence on EIB in obese adolescents. Thus, considering the relevance of EIB in obesity and the importance of clinical strategies, in this study we have explored the EIB frequency and the associated risk factors in obese adolescents submitted to long-term interdisciplinary therapy.

\section{Methods}

\section{Population}

After a sample size power calculation, a total of 55 (15-19 years old) obese adolescents were enrolled to par- 


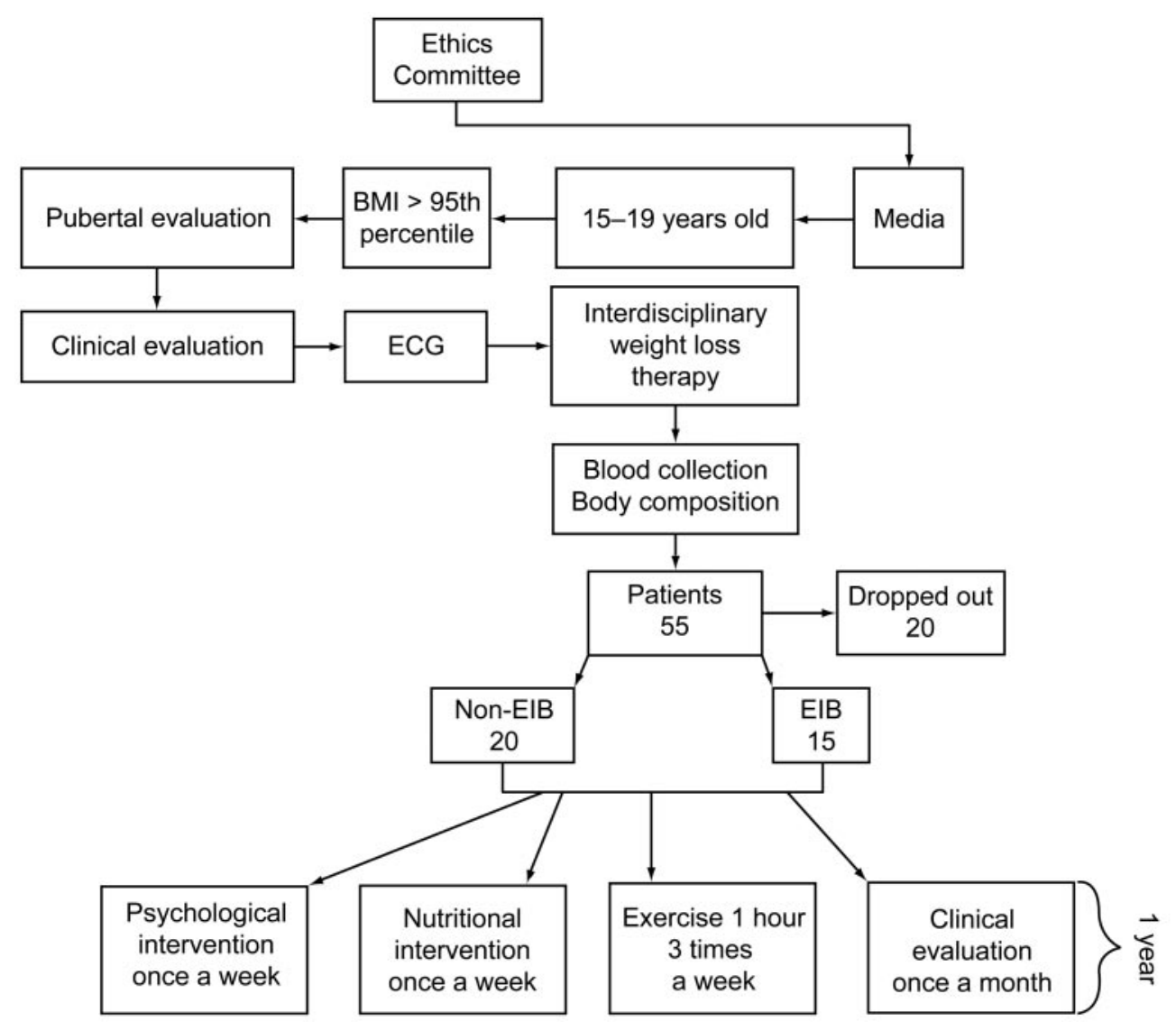

Fig. 1. Study protocol diagram. BMI = body mass index. ECG = electrocardiogram. EIB = exercise-induced bronchospasm.

ticipate in the Interdisciplinary Obesity Program of the Universidade Federal de São Paulo Escola Paulista de Medicina (UNIFESP-EPM) (Fig. 1). The study occurred at the Sleep Institute in the Centro de Estudos em Psicobiologia e Exercício - Grupo de Estudos da Obesidade (CEPEGEO) obesity interdisciplinary program, São Paulo, Brazil. The data were obtained in 2008 and 2009, when lung function was initially evaluated. The mean \pm SD age was $16 \pm 1.5$ years. The mean \pm SD body mass index (BMI) was $36 \pm 5 \mathrm{~kg} / \mathrm{m}^{2}$. All participants were confirmed as meeting the inclusion criteria of post-pubertal stage $\mathrm{V}$ (based on the Tanner stages) ${ }^{28}$ and of obesity (BMI $>95$ th percentile of the Centers for Disease Control reference growth charts). ${ }^{29}$ Non-inclusion criteria were as follows: metabolic, endocrine, or identified genetic diseases; viral diseases; previous drug use; cardiac or pulmonary diseases; and smoking. ${ }^{6}$

This study was performed in accordance with the principles of the Declaration of Helsinki, and was formally approved by the institutional ethics committee UNIFESPEPM (0135/04). Informed consent was obtained from all subjects and/or their parents, and participation of the adolescents and their families was voluntary.

\section{Study Protocol and Medical Screening}

The subjects were medically screened, and their pubertal stage and anthropometric measures were evaluated. For all subjects, the procedures were scheduled for the same time of day, to remove any influence of diurnal variation. An endocrinologist recorded their health and clinical parameters monthly (see Fig. 1).

\section{Anthropometric Measurements and Body Composition}

The subjects were weighed while wearing light clothing and no shoes, on a Filizola scale, to the nearest $0.1 \mathrm{~kg}$. Height was measured to the nearest $0.5 \mathrm{~cm}$, with a wallmounted stadiometer (Sanny ES 2030, American Medical do Brazil, São Bernardo do Campo, Brazil). BMI was calculated as body weight divided by height squared $\left(\mathrm{wt} / \mathrm{ht}^{2}\right)$.

Body composition was measured by plethysmography in a BOD POD body composition system (version 1.69, Life Measurement Instruments, Concord, California). ${ }^{30}$ Visceral and subcutaneous fat were assessed by ultrasonography, as previously described. ${ }^{31,32}$ 


\section{Serum Analysis}

Blood samples were collected at the out-patient clinic, around 8:00 $\mathrm{AM}$, after an overnight fast, by a skilled and qualified technician. After collection, the blood was centrifuged for $10 \mathrm{~min}$ at 5,000 revolutions/min and stored at $-70^{\circ} \mathrm{C}$. The materials used for collection were disposable, adequately labeled, and of recognized quality. Adiponectin (Phoenix Pharmaceuticals, Belmont, California) and leptin (Chemicon International, Millipore, Billerica, Massachusetts) levels were measured using commercially available enzyme-linked immunosorbent assay (ELISA) kits, according to the manufacturers' instructions.

\section{Evaluation of Lung Function}

Lung function was measured with a spirometer (EasyOne model 2001, ndd Medizintechnik, Zürich, Switzerland), according to American Thoracic Society criteria. ${ }^{33}$ The highest of 3 technically appropriate measurements was recorded. While the subjects were performing the maneuver, volume-time and flow-volume curves were followed on the screen. FVC (L), $\mathrm{FEV}_{1}(\mathrm{~L}), \mathrm{FEV}_{1} / \mathrm{FVC}(\%)$, and peak expiratory flow (L/s) were measured, and predicted values were obtained. ${ }^{34}$

The diagnosis of asthma was made according to American Thoracic Society guidelines. ${ }^{33}$ Specifically, the patients who presented a 6-month or longer history of recurrent chest symptoms, such as coughing, dyspnea, and wheezing, that were relieved by bronchodilator treatment, and whose spirometry demonstrated reversible air-flow limitation were not included in the study. The International Study of Asthma and Allergy in Childhood (ISAAC) questionnaire was used to assess asthmarelated symptoms. ${ }^{35}$

\section{Exercise Challenge Test}

A standardized exercise challenge test consisted of $8 \mathrm{~min}$ on a treadmill, and was initiated at a speed of $1 \mathrm{~km} / \mathrm{h}$ and a $0 \%$ inclination, increasing $1.5 \mathrm{~km} / \mathrm{h}$ and a $2.5 \%$ inclination after each 30 -second period for 2 minutes, until the subject achieved $6 \mathrm{~km} / \mathrm{h}$ and a $10 \%$ level of inclination. The challenge was conducted by having subjects run for 8 min while inhaling air through their mouths, at a work load that increased the heart rate to $80 \%$ of the age-predicted maximum..$^{36}$ During the days of testing, mean temperature and relative humidity were $25 \pm 5^{\circ} \mathrm{C}$ and $41 \pm 10 \%$, respectively. The study was conducted in the afternoon (1:00-5:00 PM).

Spirometric measurements were made immediately before and at 2, 5, 10, 15, 20, 25, and 30 min after exercise. To measure EIB, the maximal change in $\mathrm{FEV}_{1}$ was calculated as:
$\left[\left(\mathrm{FEV}_{1}\right.\right.$ at baseline - lowest $\mathrm{FEV}_{1}$ after exercise $) /$

$$
\mathrm{FEV}_{1} \text { at baseline] } \times 100 \%
$$

EIB diagnosis was defined as a $15 \%$ or greater reduction in $\mathrm{FEV}_{1}$ after exercise, compared to $\mathrm{FEV}_{1}$ at baseline. As previously mentioned, the prior history of EIB was evaluated by the ISSAC questionnaire. ${ }^{37}$

\section{Research Design}

A 1-year interdisciplinary weight loss therapy combined exercise training with medical, nutritional, and psychological therapies. The use of an interdisciplinary approach as a criterion has been suggested by the World Health Organization. ${ }^{38}$ All measurements were performed at baseline and after 6 months (short-term) and 1 year (long-term) of therapy.

\section{Psychological Therapy}

During 1 year of interdisciplinary therapy, the adolescents received psychological orientation for one hour in a weekly group session. A psychologist discussed body image and eating disorders, as well as binge eating disorders, and their signs, symptoms, and health consequences. The psychologist also discussed the relationship between emotions and food, as well as familial problems, in a group setting. Individualized psychological therapy was recommended when behavioral alterations were found, including depression, anxiety symptoms, or poor dietary habits such as bulimia, anorexia nervosa, and binge eating. ${ }^{39}$

\section{Nutritional Therapy}

Once a week for 1 year, the adolescents had nutritional lessons regarding topics such as the food pyramid, food record, weight loss diets, diet and light concepts, fat and cholesterol, and eating disorders. Energy intake was set at the levels recommended by the dietary reference for subjects with low levels of physical activity of the same age and sex. ${ }^{40}$ A 3-day dietary record was made for each adolescent to help his/her parents. Portions were measured in terms of familiar volumes and sizes. The nutritionist explained to the parents and the adolescents how to record food consumption. These dietary data were transferred to a computer by the same nutritionist, allowing for nutrient composition analysis by a software program developed at UNIFESP-EPM (Nutwin for Windows, version 1.5) based on Western and local food tables.

\section{Physical Therapy}

An aerobic and resistance training regimen was performed 3 times a week for 1 year. Each session included 
30 min of aerobic training plus 30 min of resistance training. The volunteers were instructed to invert the order of the exercises at each training session; in one session, the adolescent started the training session with aerobic exercises, and in the subsequent session, the same adolescent started with resistance training. Aerobic training consisted of running on a motor-driven treadmill (model TR 9700HR, Life Fitness, Schiller Park, Illinois) at the cardiac frequency intensity of ventilatory threshold I ( \pm 4 beats/min), which was determined by the results of an initial oxygen uptake test for aerobic exercise (cycle-ergometer and treadmill). In addition, the maximal $\mathrm{O}_{2}$ consumption $\left(\dot{\mathrm{V}}_{\mathrm{O}_{2}} \max \right)$ values were obtained from the oxygen uptake tests.

The physiologists controlled the cardiac frequency, which was measured with a cardiometer at 5 min intervals during all training sessions (FS1, Polar Electro, Kempele, Finland). The exercise program was based on the American College of Sports Medicine recommendations. ${ }^{41} \mathrm{We}$ used exercises for the main muscle groups (bench press, leg press, sit-ups, lat pull-down, hamstring curls, lower back, military press, calf raises, arm curls, and triceps pushdown), and the order of the exercises was strictly followed by the group.

The first 2 weeks of resistance training were for adaptation to training and learning other movements ( 3 sets of 15-20 maximal repetitions). Following this adaptation period, the training load was adjusted by increasing the weight and intensity, and by decreasing the number of repetitions to between $6-20$ for each of the 3 sets. The following rest intervals were allowed between series and exercises: 15-20 maximal repetitions $=45$ seconds, $10-12$ maximal repetitions $=1 \mathrm{~min}$, and 6 -8 maximal repetitions $=1.5 \mathrm{~min}$. The training loads were adjusted in each training session and evaluated according to the increase in the strength of the participants. Therefore, training was conducted with maximal repetitions. During exercise therapy, the EIB subjects were accompanied by a physical therapist who controlled their symptoms.

\section{Statistical Analysis}

Statistical analyses were performed using software (Statistica, version 7.0 for Windows, StatSoft, Tulsa, Oklahoma), and a sample size calculation was performed with alpha equal to .05 . The Gaussian distribution of variables was verified with the Shapiro-Wilk W test, and variables with normal distribution were expressed as the mean $\pm \mathrm{SD}$, whereas variables without normal distribution were expressed as median (minimum and maximum) in a descriptive table. The variables that did not present a normal distribution were leptin and adiponectin concentrations and the adiponectin/leptin ratio; for these variables, non-parametric methods were used.
The comparisons between the measurements of the parametric variables before intervention and 6 months and 1 year after intervention were determined by repeated measures analysis of variance. The Wilcoxon signed-rank test and Mann-Whitney U test were used to analyze the non-parametric variables.

Logistic regression analysis was used to ascertain the risk factors to EIB occurrence at baseline. The analysis was performed with all the subjects. The EIB diagnosis was set as a dependent variable in different models. First, the data were evaluated with a simple regression of the independent variables (body mass, $\dot{\mathrm{V}}_{\mathrm{O}_{2}} \max , \mathrm{FEV}_{1}$, adiponectin levels, leptin levels, or adiponectin/leptin ratio), whereas the EIB diagnosis was the dependent variable. Then a multiple regression was performed, considering the same variables as independent and the EIB diagnosis as dependent, but this analysis was adjusted for age and sex.

Furthermore, a simple linear regression was used, considering $\mathrm{FEV}_{1}$ as the dependent variable and leptin levels or BMI as independent variables to investigate if the $\mathrm{FEV}_{1}$ values had underlying associations with leptin levels and BMI values at baseline.

We assessed the correlation between delta values of EIB associated risk factors and lung function $(\Delta=$ the difference of values between 6 months or 1 year and baseline). The Pearson correlation coefficients were calculated to assess possible relationships between normally distributed variables, and Spearman correlation coefficients were used for non-parametric variables.

In addition, the Grubb test was used to detect outliers in the data, using software (GraphPad Prism, version 5.0 for Windows, GraphPad, San Diego, California). The results were considered statistically significant at the level of $P<.05$.

\section{Results}

At the beginning of the therapy, 55 obese adolescents were enrolled in the program. However, 35 subjects completed 1 year of therapy with more than $75 \%$ of treatment sessions. It is important to note that there were no differences for all variables between those who completed the therapy and the last known data from those who did not. The main reasons for dropping out in our study were financial and family problems, followed by school and job opportunities (see Fig. 1).

At baseline we did not find significant differences in age and BMI between the groups, after the studied population was paired by these variables according to sex. Furthermore, there were no statistically significant differences between sexes in both groups for all variables (data not shown).

One of the most important findings of the present study was that a reduction in EIB prevalence from $43 \%$ (no. $=15$ ) 
The Role of Adipokines on Exercise-Induced Bronchospasm in Obese Adolescents

Table 1. Anthropometric Variables, Body Composition, Visceral and Subcutaneous Fat, and Lung Function Variables Measured at Baseline and After Interdisciplinary Therapy in Obese Adolescents Classified by Diagnosis $(n=35)$

\begin{tabular}{|c|c|c|c|c|c|c|c|c|c|c|}
\hline & \multicolumn{5}{|c|}{ Non-EIB $($ no. $=20)$} & \multicolumn{5}{|c|}{ EIB $($ no. $=15)$} \\
\hline & Baseline & 6 Months & $\Delta$ & 1 Year & $\Delta$ & Baseline & 6 Months & $\Delta$ & 1 Year & $\Delta$ \\
\hline Female, $\%$ & 58 & & & & & 82 & & & & \\
\hline Age, $y$ & $17 \pm 1.6$ & & & & & $16 \pm 1.0$ & & & & \\
\hline Height, cm & $1.7 \pm 0.1$ & $1.7 \pm 0.1$ & 0 & $1.7 \pm 0.1$ & 0 & $1.7 \pm 0.0$ & $1.7 \pm 0.0$ & 0 & $1.7 \pm 0.0$ & 0 \\
\hline Body mass, $\mathrm{kg}$ & $102 \pm 13$ & $94 \pm 11^{*}$ & $-9 \pm 4$ & $89 \pm 10 \dagger \neq$ & $-13 \pm 7$ & $99 \pm 18$ & $93 \pm 16^{*}$ & $-6 \pm 4$ & $90 \pm 16 \dagger$ & $-9 \pm 6$ \\
\hline BMI, $\mathrm{kg} / \mathrm{m}^{2}$ & $36 \pm 5$ & $32 \pm 4 *$ & $-3 \pm 1$ & $30 \pm 4+t$ & $-5 \pm 3$ & $36 \pm 5$ & $33 \pm 5^{*}$ & $-3 \pm 1.3$ & $32 \pm 5 \dagger$ & $-4 \pm 2.1$ \\
\hline Body fat, $\%$ & $45 \pm 6$ & $39 \pm 8 *$ & $-6 \pm 3$ & $36 \pm 9 \dagger \neq$ & $-9 \pm 5$ & $48 \pm 6$ & $42 \pm 6^{*}$ & $-6 \pm 4$ & $41 \pm 5 \dagger$ & $-7 \pm 5$ \\
\hline Fat-free mass, $\%$ & $56 \pm 6$ & $61 \pm 8 *$ & $6 \pm 3$ & $64 \pm 9 \dagger \ddagger$ & $9 \pm 5$ & $53 \pm 5$ & $58 \pm 6^{*}$ & $10 \pm 15$ & $59 \pm 5 \dagger$ & $11 \pm 16$ \\
\hline Visceral fat, $\mathrm{cm}$ & $4.4 \pm 1.1$ & $3.3 \pm 1.0^{*}$ & $-1.1 \pm 0.8$ & $2.7 \pm 0.9 \dagger \ddagger$ & $-1.7 \pm 0.9$ & $3.8 \pm 0.9$ & $3.2 \pm 1.0^{*}$ & $-0.6 \pm 1.3$ & $2 \pm 0.7 \dagger t$ & $-1.7 \pm 1.0$ \\
\hline Subcutaneous fat, $\mathrm{cm}$ & $4.0 \pm 0.9$ & $3.2 \pm 0.9 *$ & $-0.9 \pm 1.0$ & $3.1 \pm 0.5 \dagger$ & $-1.0 \pm 0.7$ & $4.0 \pm 1.1$ & $3.3 \pm 0.6$ & $-0.7 \pm 0.8$ & $3.0 \pm 0.7 \dagger$ & $-0.9 \pm 1.1$ \\
\hline $\mathrm{FVC}, \%$ & $99 \pm 9$ & $105 \pm 10$ & $6 \pm 10$ & $118 \pm 12 \dagger \ddagger$ & $19 \pm 9$ & $92 \pm 9$ & $99 \pm 11 *$ & $7 \pm 9$ & $114 \pm 13 \dagger t$ & $22 \pm 12$ \\
\hline $\mathrm{FEV}_{1}, \%$ & $91 \pm 7$ & $102 \pm 7 *$ & $11 \pm 8$ & $115 \pm 9 \dagger \ddagger$ & $25 \pm 10$ & $85 \pm 3$ & $96 \pm 9 *$ & $11 \pm 9$ & $112 \pm 9 \dagger+$ & $28 \pm 10$ \\
\hline $\mathrm{FEV}_{1} / \mathrm{FVC}, \%$ & $97 \pm 8$ & $100 \pm 5$ & $3 \pm 7$ & $100 \pm 7$ & $3 \pm 6$ & $97 \pm 8$ & $98 \pm 10$ & $1 \pm 6$ & $102 \pm 7$ & $5 \pm 9$ \\
\hline PEF, \% & $95 \pm 14$ & $105 \pm 15^{*}$ & $10 \pm 11$ & $113 \pm 12 \dagger \neq$ & $14 \pm 29$ & $90 \pm 6$ & $101 \pm 14^{*}$ & $12 \pm 15$ & $102 \pm 13 \dagger$ & $13 \pm 14$ \\
\hline$\dot{\mathrm{V}}_{\mathrm{O}_{2}} \max , \mathrm{mL} / \mathrm{kg} / \min$ & $16 \pm 2$ & $19 \pm 3$ & $2 \pm 4$ & $22 \pm 7 \dagger$ & $6 \pm 7$ & $15 \pm 5$ & $16 \pm 5$ & $1 \pm 1.7$ & $18 \pm 6$ & $2 \pm 2$ \\
\hline $\begin{array}{l}\text { Adiponectin/leptin ratio, } \\
\text { median (range) }\end{array}$ & $\begin{array}{c}0.1 \\
(0.0-6.3)\end{array}$ & $\begin{array}{c}0.2 \\
(0.1-3.0)^{*}\end{array}$ & $\begin{array}{c}0.05 \\
(-3.9 \text { to } 2.7)\end{array}$ & $\begin{array}{c}0.5 \\
(0.1-4.3) \dagger\end{array}$ & $\begin{array}{c}0.16 \\
(-3.0 \text { to } 4.0)\end{array}$ & $\begin{array}{c}0.1 \\
(0.1-0.3)\end{array}$ & $\begin{array}{c}0.3 \\
(0.1-0.7)^{*}\end{array}$ & $\begin{array}{c}0.1 \\
(0.0-0.5)\end{array}$ & $\begin{array}{c}0.2 \\
(0.1-0.5) \dagger \ddagger\end{array}$ & $\begin{array}{c}0.0 \\
(0.0-0.3)\end{array}$ \\
\hline \multicolumn{11}{|c|}{$\begin{array}{l}\text { Values are mean } \pm \mathrm{SD} \text {. } \\
* \text { Baseline vs } 6 \text { months } P=.01 . \\
\dagger \text { Baseline vs } 1 \text { year } P=<.001 . \\
\ddagger 6 \text { months vs } 1 \text { year } P=.01 . \\
\text { EIB }=\text { exercise-induced bronchospasm } \\
\mathrm{BMI}=\text { body mass index } \\
\mathrm{PEF}=\text { peak expiratory flow } \\
\dot{\mathrm{V}}_{\mathrm{O}_{2}} \max =\text { maximal } \mathrm{O}_{2} \text { consumption }\end{array}$} \\
\hline
\end{tabular}

to $13 \%($ no. $=2)$ and $0 \%$ was shown, respectively, for short- and long-term therapy in all analyzed obese subjects.

According to EIB diagnosis at baseline, the volunteers were divided into 2 groups: non-EIB group (no. $=20$ ) and EIB group (no. = 15) (Table 1). When the groups were compared, statistical differences between analyzed variables in all the times of evaluation were not observed. In both groups a significant reduction in all anthropometric variables was observed.

Furthermore, after therapy, lung function improved (see Table 1) and was paralleled by a reduction in the percentage of fall in $\mathrm{FEV}_{1}$ and $\mathrm{FEV}_{1} / \mathrm{FVC}$ values after the exercise bronchoprovocation test in the EIB group (Fig. 2). Moreover, the volunteers of the EIB group did not present previous history of EIB evaluated by the ISAAC questionnaire, and did not receive medication to control symptoms of EIB (data not shown).

Logistic regression analysis showed that low values of $\mathrm{FEV}_{1}$ were a risk factor associated with the EIB diagnosis at baseline. The adjustments for age and sex did not change this association substantially (Table 2). Furthermore, a simple linear regression was performed considering $\mathrm{FEV}_{1}$ as the dependent variable and leptin levels or BMI as independent variables to investigate if the lower $\mathrm{FEV}_{1}$ had underlying associations with leptin levels and BMI values at baseline; however, these variables were not predictors of $\mathrm{FEV}_{1}$ values (data not shown).

Another finding from the present investigation was that the adiponectin/leptin ratio (see Table 1) and the adiponectin concentration increased significantly (Fig. 3), while the leptin levels decreased significantly after therapy, in both groups (Fig. 4), although the state of hyperleptinemia was maintained in the EIB group.

Another important result was that changes in lung function were negatively correlated with changes in anthropometric variables and leptin levels in both groups. On the other hand, positive correlations were observed among changes in lung function and adiponectin levels and $\dot{\mathrm{V}}_{\mathrm{O}_{2}}$ max in both groups (Table 3). Nevertheless, the EIB group did not have a significant increase in $\dot{\mathrm{V}}_{\mathrm{O}_{2}}$ max (see Table 1).

\section{Discussion}

In the present study, interdisciplinary therapy promoted a great control of the EIB occurrence in all subjects, paralleled by an increase in lung function and improvement in pro-/anti-inflammatory adipokines profile. Furthermore, we observed that low $\mathrm{FEV}_{1}$ values were a risk factor associated with EIB diagnosis at baseline.

In this context, pharmacologic and non-pharmacologic methods can be used in the management of EIB. ${ }^{19}$ Pro- 


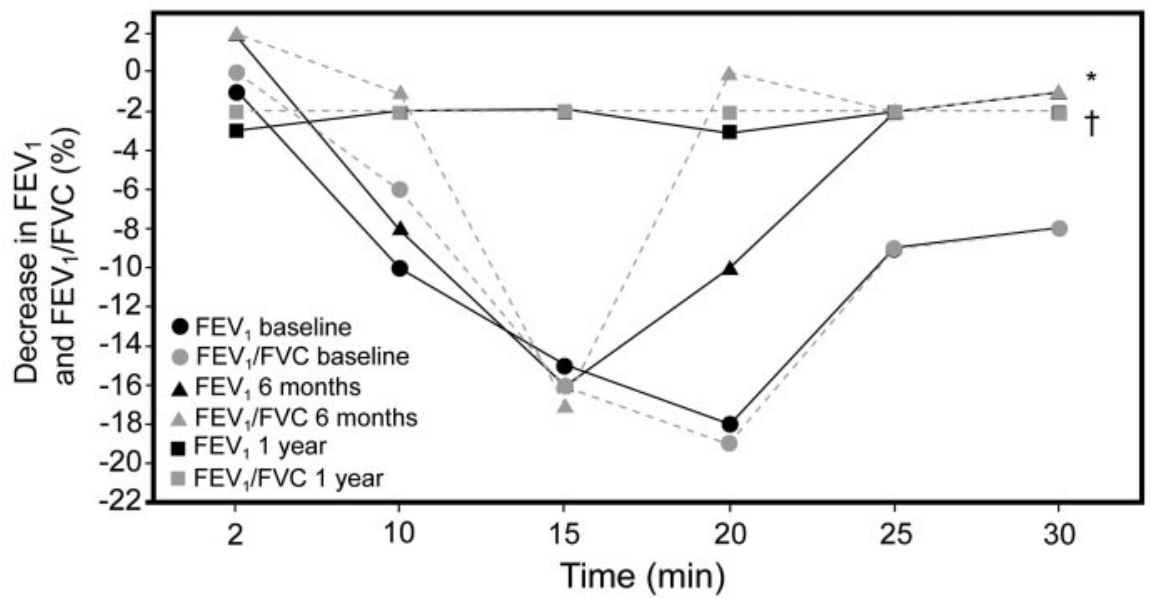

Fig. 2. Percentage of decrease in $\mathrm{FEV}_{1}$ and $\mathrm{FEV}_{1} / \mathrm{FVC}$ values after bronchoprovocation test in the exercise-induced bronchospasm group. ${ }^{*} P=.02$ between baseline and short-term therapy. $\dagger P=.01$ between baseline and long-term therapy.

Table 2. Logistic Regression Analysis of the Relationship Between EIB and Its Possible Associated Risk Factors at Baseline

\begin{tabular}{lcc}
\hline \hline & $\begin{array}{c}\text { Crude Odds } \\
\text { Ratio (95\% CI) }\end{array}$ & $\begin{array}{c}\text { Adjusted Odds } \\
\text { Ratio (95\% CI)* }\end{array}$ \\
\hline Body mass & $0.98(0.93-1.03)$ & $0.99(0.94-1.05)$ \\
$\mathrm{FEV}_{1} \%$ & $0.76(0.61-0.94)$ & $0.71(0.53-0.94)$ \\
$\dot{\mathrm{V}}_{\mathrm{O}_{2}} \max$ & $0.91(0.71-1.18)$ & $0.98(0.75-1.31)$ \\
Adiponectin levels & $1.08(0.85-1.37)$ & $0.95(0.09-10.2)$ \\
Leptin levels & $1.03(0.98-1.08)$ & $0.99(0.93-1.08)$ \\
Adiponectin/leptin ratio & $0.26(0.04-17.7)$ & $0.95(0.08-10,2)$
\end{tabular}

* Analyses are adjusted only for age and sex.

$\mathrm{EIB}=$ exercise-induced bronchospasm

$\dot{\mathrm{V}}_{\mathrm{O}_{2}} \max =$ maximal $\mathrm{O}_{2}$ consumption

posed options for non-pharmacologic management include physical conditioning, nasal breathing, incorporating a warm-up before and a cool-down period after exercise, avoidance of cold weather or environmental allergens, and using a face mask or other aid to warm and humidify inhaled air. ${ }^{18,19}$ Recent results also suggests that dietary modifications may play a role in controlling EIB in asthmatics. ${ }^{25}$ However, to our knowledge, this is the first study that has evaluated the effect of an interdisciplinary therapy of 1 year on EIB frequency and possible mechanisms involved in this change, such as inflammatory factors (leptin, adiponectin and adiponectin/leptin ratio) in non-asthmatic obese adolescents.

Obesity negatively affects the respiratory and other systems in many ways, and previous studies have demonstrated that increased body weight has been associated with bronchial hyper-responsiveness in obese patients, ${ }^{42}$ confirming the importance of attenuating the inflammatory process related to obesity and respiratory conditions. Nevertheless, studies assessing EIB frequency in non-asth-

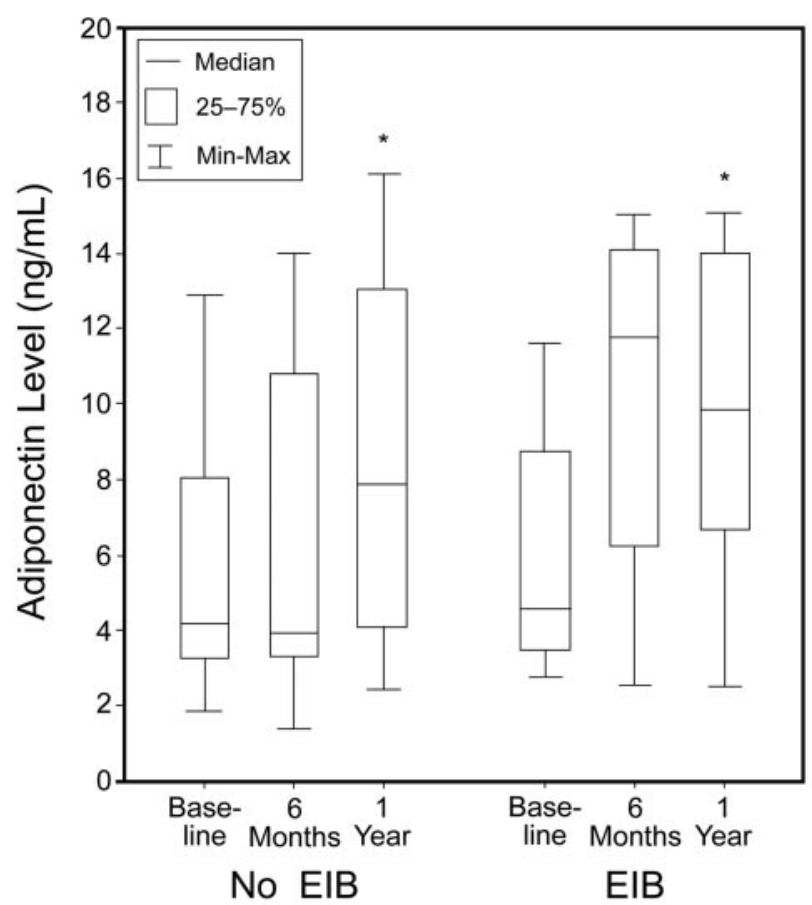

Fig. 3. The adiponectin levels measured at baseline and after 6 months and 1 year of interdisciplinary therapy in both groups. * Baseline versus 1 year of therapy $P=<.05$.

matic obese children and adolescents have found conflicting results. $6,7,10,11$

In the present investigation, we observed that 1 year of interdisciplinary therapy decreased EIB frequency; this fact was evidenced by the proportional change in $\mathrm{FEV}_{1}$ and $\mathrm{FEV}_{1} / \mathrm{FVC}$ after exercise in the EIB group (see Fig. 2). This is a relevant finding, considering that some studies have demonstrated that non-asthmatic obese individuals have a greater EIB frequency, compared to lean individ- 


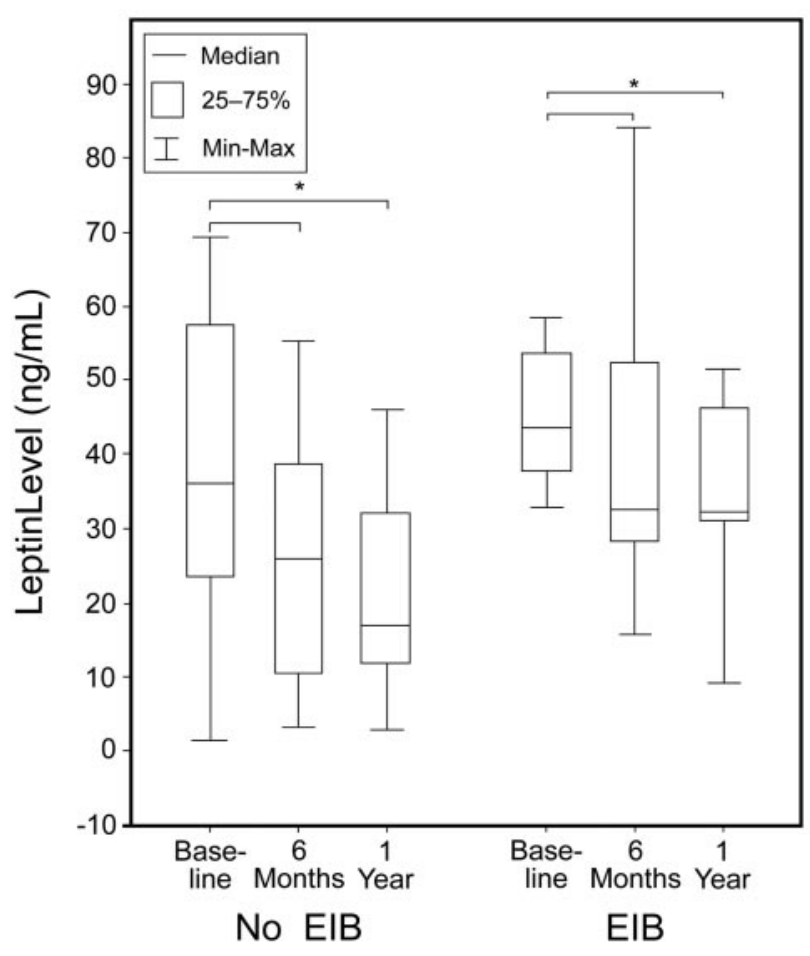

Fig. 4. The leptin levels measured at baseline and after 6 months and 1 year of interdisciplinary therapy in both groups. * Baseline versus 1 year of therapy $P=<.05$.

uals. ${ }^{6,7}$ Furthermore, this condition can be a restriction to the practice of physical exercise and consequently contributes to sedentarism, ${ }^{43}$ as well to a vicious cycle between causes and consequences linking obesity and respiratory diseases. ${ }^{44}$

The sedentary state of obese individuals further complicates matters by putting an added strain on the respiratory system: their decreased $\dot{\mathrm{V}}_{\mathrm{O}_{2}}$ max causes this system to work much harder for an equivalent level of physical activity, even at low levels. ${ }^{43}$ It should also be considered that the ventilatory reserves in the obese are limited by their ability to support the increased muscle oxygen requirements during exercise, because the lungs do not increase in size commensurate with the subject's added weight. ${ }^{45}$

In our study, differences in the $\dot{\mathrm{V}}_{\mathrm{O}_{2}}$ max values were not found between the groups. However, after therapy, the improvement in $\mathrm{FEV}_{1}$ was correlated with the change in $\dot{\mathrm{V}}_{\mathrm{O}_{2}}$ max. This result was expected because there was an improvement in lung function after therapy, and consequently in the ventilatory reserve, with an increase in $\dot{\mathrm{V}}_{\mathrm{O}_{2}}$ max values (Table 4). ${ }^{45}$ Furthermore, exercise programs involving aerobic activity have demonstrated a benefit in cardiorespiratory fitness, and consequently in the exercise tolerance and EIB frequency in asthmatics. ${ }^{26,27}$
The decrease in EIB frequency was followed by improvements in lung function (see Table 1), in agreement with previous studies. ${ }^{46,47}$ This increase in $\mathrm{FEV}_{1}$ and $\mathrm{FEV}_{1} /$ FVC may reflect the enhancement in lung volumes, a wellknown effect of weight loss in obese patients, ${ }^{46-48}$ suggesting an important role of an integrated clinical approach to control of chronic diseases. ${ }^{38}$

Moreover, one of the most important findings in this study was that a low $\mathrm{FEV}_{1}$ value was a risk factor associated with EIB at baseline, when adjusted for age and sex. There are some disagreements on the role of the pre-challenge $\mathrm{FEV}_{1}$ in the association between obesity and airway hyper-responsiveness. Whereas in some studies $\mathrm{FEV}_{1}$ remained unchanged or increased in obese individuals, ${ }^{49,50}$ others demonstrated that increased body fat or fat distribution impaired mechanical ventilation, with reduced ventilatory function and small tidal volumes, with low smooth airway stretch. ${ }^{50,51}$ Reduced smooth muscle stretch results in a "latch phase" with less actin-myosin cycling increasing airway hyper-responsiveness. ${ }^{13}$

In addition, the lung volume is a major determinant of the bronchoconstrictor response. Thus, changes in lung volume act to alter the forces of interdependence between airways and parenchyma that oppose airway smooth muscle contraction. ${ }^{52}$ Therefore, we suppose that this is the main mechanism for EIB occurrence in our study.

To better explore the other mechanisms involved in EIB occurrence in obese adolescents, a regression analysis was performed to investigate the role of leptin concentrations and adiposity measures on $\mathrm{FEV}_{1}$ values; however, these variables were not predictors of low $\mathrm{FEV}_{1}$ values at baseline (data not shown). This aspect needs to be investigated in future research with a larger cohort.

Moreover, after treatment, we showed that $\mathrm{FEV}_{1}$ values were negatively correlated with changes in leptin concentration. Nevertheless, after 1 year of therapy, the EIB group did not normalize the leptin values, remaining in a state of hyperleptinemia. Altogether, these findings suggest the difficulty in controlling both the neuroendocrine regulation of energy balance and the inflammatory process linking obesity and respiratory alterations.

Since its discovery, leptin has been known to play an important role in energy balance control. ${ }^{53}$ In addition, studies have observed an important function: up-regulation of inflammatory immune responses. This finding may provide a common pathogenesis mechanism, which contributes to the majority of complications of obesity. ${ }^{54} \mathrm{Lep}-$ tin's action on inflammation leads to an inflammatory state in obese subjects. ${ }^{55}$

A previous study demonstrated that leptin was negatively correlated with lung function variables. ${ }^{14}$ Furthermore, leptin infusion in mice was associated with airway hyper-responsiveness. ${ }^{13}$ Human studies have demonstrated that high leptin concentration was associated with increased 
Table 3. Correlation Coefficients of the Factors Potentially Associated With EIB in Obese Adolescents at Short and Long Term After Therapy

\begin{tabular}{|c|c|c|c|c|c|c|c|c|c|c|c|c|}
\hline & \multicolumn{6}{|c|}{ Short Term } & \multicolumn{6}{|c|}{ Long Term } \\
\hline & \multicolumn{3}{|c|}{ Non-EIB } & \multicolumn{3}{|c|}{ EIB } & \multicolumn{3}{|c|}{ Non-EIB } & \multicolumn{3}{|c|}{ EIB } \\
\hline & $\underset{\%}{\Delta \mathrm{FVC}}$ & $\underset{\%}{\Delta \mathrm{FEV}_{1}}$ & $\underset{\%}{\Delta \mathrm{PEF}}$ & $\underset{\%}{\Delta \mathrm{FVC}}$ & $\underset{\%}{\Delta \mathrm{FEV}_{1}}$ & $\underset{\%}{\Delta \mathrm{PEF}}$ & $\underset{\%}{\Delta \mathrm{FVC}}$ & $\underset{\%}{\Delta \mathrm{FEV}_{1}}$ & $\underset{\%}{\Delta \mathrm{PEF}}$ & $\underset{\%}{\Delta \mathrm{FVC}}$ & $\underset{\%}{\Delta \mathrm{FEV}_{1}}$ & $\underset{\%}{\Delta \mathrm{PEF}}$ \\
\hline$\Delta$ Body mass & $-0.55^{*}$ & -0.19 & -0.30 & 0.17 & -0.26 & -0.09 & -0.06 & 0.04 & -0.42 & -0.24 & -0.35 & -0.14 \\
\hline$\Delta$ Body fat $\%$ & -0.19 & -0.10 & 0.03 & $-0.41 *$ & -0.21 & -0.05 & -0.21 & $-0.38^{*}$ & -0.13 & -0.17 & 0.16 & -0.15 \\
\hline$\Delta$ Body mass index & $-0.50^{*}$ & -0.20 & -0.31 & -0.27 & -0.15 & -0.03 & -0.08 & 0.03 & $-0.36^{*}$ & -0.07 & -0.22 & -0.05 \\
\hline$\Delta$ Visceral fat & $-0.60 *$ & -0.10 & -0.14 & $-0.38^{*}$ & -0.01 & $-0.66^{*}$ & -0.18 & 0.06 & -0.02 & $-0.48^{*}$ & 0.03 & -0.24 \\
\hline$\Delta \dot{\mathrm{V}}_{\mathrm{O}_{2}} \max$ & 0.15 & 0.13 & 0.13 & $0.36^{*}$ & 0.16 & 0.15 & $0.50^{*}$ & 0.26 & $0.50 *$ & 0.00 & $0.40 *$ & 0.00 \\
\hline$\Delta$ Adiponectin & $0.52 *$ & 0.04 & 0.16 & $0.38 *$ & -0.02 & 0.34 & -0.18 & 0.15 & 0.08 & $0.47 *$ & 0.17 & 0.07 \\
\hline$\Delta$ Leptin & -0.17 & -0.03 & -0.08 & $-0.83^{*}$ & $-0.40^{*}$ & -0.26 & -0.34 & 0.01 & -0.40 & $0.57 *$ & $-0.66^{*}$ & -0.08 \\
\hline \multicolumn{13}{|c|}{$\begin{array}{l}* P<.05 \\
\text { EIB }=\text { exercise-induced bronchospasm } \\
\mathrm{PEF}=\text { peak expiratory flow } \\
\dot{\mathrm{V}}_{\mathrm{O}_{2}} \max =\text { maximal } \mathrm{O}_{2} \text { consumption }\end{array}$} \\
\hline
\end{tabular}

prevalence of asthma and a trend for wheezing in asthmatics. ${ }^{56,57} \mathrm{~A}$ recent study showed that the pro-inflammatory effects of obesity on the airway are probably not due to a direct effect of leptin on airway smooth muscle. In this sense, another mechanism proposed is that the leptin effects are a result of proliferation inhibition on human airway smooth muscle. ${ }^{14}$ Therefore, the main effects of leptin in this process are on airway inflammation and lung development. ${ }^{13,14,56,57}$

The reports are scarcer on the link between obesityassociated EIB and adiponectin, which is an obesity-related biomarker. Studies associating adipokines and asthma have documented a protective effect of high adiponectin concentration, although only in asthmatics patients. ${ }^{15,58}$

Thus, one finding from this study is that the improvement in $\mathrm{FEV}_{1}$ values was positively correlated with changes in adiponectin concentration in non-asthmatic obese adolescents. The primary metabolic effects of adiponectin are on glucose regulation and fatty acid metabolism, but it also has an anti-inflammatory effect. ${ }^{59,60}$ Thus, the decreased adiponectin concentrations commonly observed in the obese, including adolescents, could contribute to the development of airway hyper-responsiveness. ${ }^{17}$ The significant increment in adiponectin and in adiponectin/leptin ratio after treatment can suggest a better control of subclinical inflammation related to obesity in these patients.

Taken together, this study demonstrated that interdisciplinary therapy promoted an improvement in lung function and anti-inflammatory profile, as well as a reduction in adiposity measures; however, the EIB group remained with higher leptin levels and did not improve their $\dot{\mathrm{V}}_{\mathrm{O}_{2}} \max$ values. These findings reinforce the importance of the practice of non-pharmacologic therapy for the treatment of the common conditions related to obesity and respiratory alterations in non-asthmatic obese adolescents.
The lack of a control group represents a limitation of the present study. However, it should be mentioned that the original objective was to assess the effects of long-term interdisciplinary therapy on EIB frequency and inflammatory risk factors associated in obese adolescents. Further investigation including a control group and long-term follow-up are needed.

\section{Conclusions}

This study demonstrated a decrease in EIB frequency, paralleled by an increase in lung function and an improvement in the pro-/anti-inflammatory profile among obese adolescents. Additionally, this kind of treatment effectively ameliorates the hormonal profile and obesity in adolescents.

\section{REFERENCES}

1. Masoli M, Fabian D, Holt S, Beasley R. The global burden of asthma: executive summary of the GINA Dissemination Committee report. Allergy 2004;59(5):469-478.

2. World Health Organization. Obesity: preventing and managing the global epidemic. Report of a WHO Consultation on Obesity, 3-5 June 1997, Geneva.

3. Instituto Brasileiro de Geografia e Estatística (IBGE) 2010. Antropometria e estado nutricional de crianças, adolescentes e adultos no Brasil. http://www.ibge.gov.br/home/presidencia/noticias/ noticia_visualiza.php?id_noticia $=1699 \& i d \_p a g i n a=1$. Accessed March 15, 2012.

4. Sood A. Altered resting and exercise respiratory physiology in obesity. Clin Chest Med 2009;30(3):445-454.

5. Ochs-Balcom HM, Grant BJ, Muti P, Sempos CT, Freudenheim JL, Trevisan M, et al. Pulmonary function and abdominal adiposity in the general population. Chest 2006;129(4):853-862.

6. Ulger Z, Demir E, Tanaç R, Gökşen D, Gülen F, Darcan S, et al. The effect of Childhood obesity on respiratory function tests and airway hyperresponsiveness. Turk J Pediatr 2006;48(1):43-50. 
7. Del Río-Navarro BE, Cisneros-Rivero M, Berber-Eslava A, EspínolaReyna G, Sienra-Monge J. Exercise induced bronchospasm in asthmatic and non-asthmatic obese children. Allergol Immunopathol (Madr) 2000;28(1):5-11.

8. Lopes WA, Radominski RB, Rosário Filho NA, Leite N. Exerciseinduced bronchospasm in obese adolescents. Allergol Immunopathol (Madr) 2009;37(4):175-179.

9. Haby MM, Anderson SD, Peat JK, Mellis CM, Toelle BG, Woolcock AJ. An exercise challenge protocol for epidemiological studies of asthma in children: comparison with histamine challenge. Eur Respir J 1994;(1):43-49.

10. Kaplan TA, Montana E. Exercise-Induced bronchospasm in nonasthmatic obese children. Clin Pediatr (Phila) 1993;32(4):220-225.

11. Gökbel H, Ataş. Exercise-induced bronchospasm in nonasthmatic obese and nonobese boys. Sports Med Phys Fitness 1999;39(4):361364.

12. Shore SA. Obesity, airway hyperresponsiveness, and inflammation. J Appl Physiol 2010;108(3):735-743.

13. Shore SA, Fredberg JJ. Obesity, smooth muscle, and airway hyperresponsiveness. J Allergy Clin Immunol 2005;115(5):925-927.

14. Nair P, Radford K, Fanat A, Janssen LJ, Peters-Golden M, Cox PG. The effects of leptin on airway smooth muscle responses. Am J Respir Cell Mol Biol 2008;39(4):475-481.

15. Kim KW, Shin YH, Lee KE, Kim ES, Sohn MH, Kim KE. Relationship between adipokines and manifestations of childhood asthma. Pediatr Allergy Immunol 2008;19(6):535-540.

16. Oyama LM, do Nascimento CM, Carnier J, de Piano A, Tock L, Sanches Pde L, et al. The role of anorexigenic and orexigenic neuropeptides and peripheral signals on quartiles of weight loss in obese adolescents. Neuropeptides 2010;44(6):467-474.

17. Winer JC, Zern TL, Taksali SE, Dziura J, Cali AM, Wollschlager M, et al. Adiponectin in childhood and adolescent obesity and its association with inflammatory markers and components of the metabolic syndrome. J Clin Endocrinol Metab 2006;91(11):4415-4423.

18. Millward DT, Tanner LG, Brown MA. Treatment options for the management of exercise-induced asthma and bronchoconstriction. Phys Sportsmed 2010;38(4):74-80.

19. Parsons JP. Current concepts in the diagnosis and management of exercise-induced bronchospasm. Phys Sportsmed 2010;38(4):48-53.

20. Bisgaard H. Role of leukotrienes in asthma pathophysiology. Pediatr Pulmonol 2000;30(2):166-176.

21. Weiler JM, Nathan RA, Rupp NT, Kalberg CJ, Emmett A, Dorinsky PM. Effect of fluticasone/salmeterol administered via a single device on exercise-induced bronchospasm in patients with persistent asthma. Ann Allergy Asthma Immunol 2005;94(1):65-72.

22. Anderson SD, Lambert S, Brannan JD, Wood RJ, Koskela H, Morton AR, et al. Laboratory protocol for exercise asthma to evaluate salbutamol given by two devices. Med Sci Sports Exerc 2001;33(6): 893-900.

23. Hancox RJ, Subbarao P, Kamada D, Watson RM, Hargreave FE, Inman MD. Beta2-agonist tolerance and exercise-induced bronchospasm. Am J Respir Crit Care Med 2002;165(8):1068-1070.

24. Nelson HS, Weiss ST, Bleecker ER, Yancey SW, Dorinsky PM. SMART Study Group. The Salmeterol Multicenter Asthma Research Trial: a comparison of usual pharmacotherapy for asthma or usual pharmacotherapy plus salmeterol. Chest 2006;129(1):15-26.

25. Mickleborough TD, Lindley MR, Ionescu AA, Fly AD. Protective effect of fish oil supplementation on exercise-induced bronchoconstriction in asthma. Chest 2006;129(1):39-49.

26. Fanelli A, Cabral AL, Neder JA, Martins MA, Carvalho CR. Exercise training on disease control and quality of life in asthmatic children. Med Sci Sports Exerc 2007;39(9):1474-1480.

27. Basaran S, Guler-Uysal F, Ergen N, Seydaoglu G, Bingol-Karakoç G, Ufuk Altintas D. Effects of physical exercise on quality of life, exercise capacity and pulmonary function in children with asthma. $\mathrm{J}$ Rehabil Med 2006;38(2):130-135.

28. Tanner JM, Whitehouse RH. Clinical longitudinal standards for height, weight, weight velocity and stages of puberty. Arch Dis Child 1976;51(3):170-179.

29. Centers for Disease Control and Prevention. Prevalence of overweight among children and adolescents: United States 1999-2002. http://www.cdc.gov/nchs/data/hestat/overweight/overweight99.htm. Accessed January 30, 2012.

30. Fields DA, Hunter GR, Goran MI. Validation of the BOD POD with hydrostatic weighing: Influence of body clothing. Int J Obes Relat Metab Disord 2000;24(2):200-205.

31. Ribeiro-Filho FF, Faria AN, Azjen S, Zanella MT, Ferreira SR. Methods of estimation of visceral fat: advantages of ultrasonography. Obes Res 2003;11(12):1488-1494.

32. Tock L, Prado WL, Caranti DA, Cristofalo DMJ, Lederman H, Fisberg M, et al. Non-alcoholic fatty liver disease in obese adolescents after multidisciplinary therapy. Eur J Gastroenterol Hepatol 2006; 18(12):1241-1245.

33. American Thoracic Society. Guidelines for assessing and managing asthma risk at work, school, and recreation. Am J Respir Crit Care Med 2004;169(7):873-881.

34. Knudson RJ, Lebowitz MD, Holberg CJ, Burrows B. Changes in the healthy maximal expiratory flow-volume curve with growth and aging. Am Rev Respir Dis 1983;127(6):725-734.

35. Weiland SK, Björkstén B, Brunekreef B, Cookson WO, von Mutius E, Strachan DP; International Study of Asthma and Allergies in Childhood Phase II Study Group. International Study Protocol: International study of asthma and allergies in childhood (ISAAC): rationale and methods. Eur Respir J 1995;8:483-491.

36. Carlsen KH, Engh G, Mork M. Exercise-induced bronchoconstriction depends on exercise load. Respir Med 2000;94(8):750-755.

37. Asher MI, Keil U, Anderson HR, Beasley R, Crane J, Martinez F, et al. International Study of Asthma and Allergies in Childhood (ISAAC): rationale and methods. Eur Respir J 1995;8(3):483-491.

38. World Health Organization. Report of a WHO consultation. In: Alwan A, King H. Definition, diagnosis and classification of diabetes mellitus and its complications. Part 1: diagnosis and classification of diabetes mellitus. Geneva, Department of Noncommunicable Disease Surveillance: World Health Organization 1999;1-59.

39. Lofrano-Prado MC, Antunes HK, do Prado WL, de Piano A, Caranti DA, Tock L, et al. Quality of life in Brazilian obese adolescents: effects of a long-term multidisciplinary lifestyle therapy. Health Qual Life Outcomes 2009;7:61.

40. NRC (National Academic Press) dietary reference intake: applications in dietary assessment. Washington, DC: National Academic Press; 2001.

41. American College of Sports Medicine. Progression models in resistance training for healthy adults. Med Sci Spor Exerc 2002;34(2): 364-380.

42. Schachter LM, Salome CM, Peat JK, Woolcock AJ. Obesity is a risk for asthma and wheeze but not airway hyperresponsiveness. Thorax 2001;56(1):4-8.

43. Wright A, Lavoie KL, Jacob A, Rizk A, Bacon SL. Effect of body mass index on self-reported exercise-triggered asthma. Phys Sportsmed 2010;38(4):61-66.

44. Beuther DA. Sutherland ER. Overweight, obesity, and incident asthma: a meta-analysis of prospective epidemiologic studies. Am J Respir Crit Care Med 2007;175(7):661-666.

45. Wasserman K, Hansen JE, Sue DY, Stringer WW, Whipp BJ. Principles of exercise testing and interpretation. Philadelphia: Lippincott Williams \& Wilkins; 2005:133-154. 
46. Hakala K, Stenius-Aarniala B, Sovijärvi A. Effects of weight loss on peak flow volumes in obese patients with asthma. Chest 2000;118(5): 1315-1321.

47. Stenius-Aarniala B, Poussa T, Kvarnström J, Grönlund EL, Ylikahri $\mathrm{M}$, Mustajoki P. Immediate and long term effects of weight reduction in obese people with asthma: randomized controlled study. BMJ 2000;320(7238):827-832.

48. Johnson JB, Summer W, Cutler RG, Martin B, Hyun DH, Dixit VD, et al. Alternate day calorie restriction improves clinical findings and reduces markers of oxidative stress and inflammation in overweight adults with moderate asthma. Free Radic Biol Med 2007;42(5):665674.

49. Li AM, Chan D, Wong E, Yin J, Nelson EA, Fok TF. The effects of obesity on pulmonary function. Arch Dis Child 2003;88(4):361-363.

50. Koenig SM. Pulmonary complications of obesity. Am J Med Sci 2001;321(4):249-279.

51. Lazarus R, Colditz G, Berkey CS, Speizer FE. Effects of body fat on ventilatory function in children and adolescents: crosssectional findings from a random population sample of school children. Pediatr Pulmonol 1997;24(3):187-194.

52. Ding DJ, Martin JG, Macklem PT. Effects of lung volume on maximal methacholine-induced bronchoconstriction in normal humans. J Appl Physiol 1987;62(3):1324-1330.
53. Frühbeck G, Jebb SA, Prentice AM. Leptin: physiology and pathophysiology. Clin Physiol 1998;18(5):399-419.

54. Loffreda S, Yang SQ, Lin HZ, Karp CL, Brengman ML, Wang DJ, et al. Leptin regulates proinflammatory immune responses. FASEB J 1998;12(1):57-65.

55. Visser M, Bouter LM, McQuillan GM, Wener MH, Harris TB. Lowgrade systemic inflammation in overweight children. Pediatrics 2001; 107(1):E13

56. Guler N, Kirerleri E, Ones U, Tamay Z, Salmayenli N, Darendeliler F. Leptin: does it have any role in childhood asthma? J Allergy Clin Immunol 2004;114(2):254-259.

57. Nagel G, Koenig W, Rapp K, Wabitsch M, Zoellner I, Weiland SK. Associations of adipokines with asthma, rhinoconjunctivitis, and eczema in German schoolchildren. Pediatr Allergy Immunol 2009; 20(1):81-88.

58. Sood A, Cui X, Qualls C, Beckett WS, Gross MD, Steffes MW, et al. Association between asthma and serum adiponectin concentration in women. Thorax 2008;63(10):877-882.

59. Fantuzzi G. Adipose tissue, adipokines, and inflammation. J Allergy Clin Immunol 2005;115(5):897-909.

60. Bruun JM, Lihn AS, Verdich C, Pedersen SB, Toubro S, Astrup A, et al. Regulation of adiponectin by adipose tissue-derived cytokines: in vivo and in vitro investigations in humans. Am J Physiol Endocrinol Metab 2003;285(3):E527-E533. 